Research

Open Access

\title{
Intensive care unit acquired infection has no impact on long-term survival or quality of life: a prospective cohort study
}

\author{
Pekka Ylipalosaari ${ }^{1}$, Tero I Ala-Kokko², Jouko Laurila², Pasi Ohtonen ${ }^{3}$ and Hannu Syrjälä ${ }^{1}$
}

\author{
1Department of Infection Control, Oulu University Hospital, P.O. Box 22, FIN-90029 OYS, Finland \\ 2Department of Anesthesiology, Division of Intensive Care, Oulu University Hospital, P.O. Box 22, FIN-90029 OYS, Finland \\ ${ }^{3}$ Departments of Anesthesiology and Surgery, Oulu University Hospital, P.O. Box 22, FIN-90029 OYS, Finland
}

Corresponding author: Pekka Ylipalosaari, pekka.ylipalosaari@oulu.fi

Received: 29 Nov 2006 Revisions requested: 9 Jan 2007 Revisions received: 1 Feb 2007 Accepted: 9 Mar 2007 Published: 9 Mar 2007

Critical Care 2007, 11:R35 (doi:10.1186/cc5718)

This article is online at: http://ccforum.com/content/11/2/R35

(C) 2007 Ylipalosaari et al.; licensee BioMed Central Ltd.

This is an open access article distributed under the terms of the Creative Commons Attribution License (http://creativecommons.org/licenses/by/2.0), which permits unrestricted use, distribution, and reproduction in any medium, provided the original work is properly cited.

\begin{abstract}
Introduction The aim of this study was to evaluate the impact of intensive care unit (ICU)-acquired infection on long-term survival and quality of life.

Methods Long-term survival was prospectively evaluated among hospital survivors who had stayed in a mixed, universitylevel ICU for longer than 48 hours during a 14-month study period during 2002 to 2003 . Health-related quality of life was assessed using the five-dimensional EuroQol (EQ-5D) questionnaire in January 2005.
\end{abstract}

Results Of the 272 hospital survivors, 83 (30.5\%) died after discharge during the follow-up period. The median follow-up time after hospital discharge was 22 months. Among patients without infection on admission, long-term mortality did not differ between patients who developed and those who did not develop an ICU-acquired infection (21.7\% versus $26.9 \%$; $P=$ $0.41)$. Also, among patients with infection on admission, there was no difference in long-term mortality between patients who developed a superimposed (35.1\%) and those who did not develop a superimposed (27.6\%) ICU-acquired infection $(P=$ 0.40). The EQ-5D response rate was $75 \%$. The patients who developed an ICU-acquired infection had significantly more problems with self-care (50\%) than did those without an ICUacquired infection (32\%; $P=0.004$ ), whereas multivariate analysis did not show ICU-acquired infection to be a significant risk factor for diminished self-care (odds ratio $=1.71,95 \%$ confidence interval $=0.65-4.54 ; P=0.28$ ). General health status did not differ between those with and those without an ICU-acquired infection, as measured using the EuroOol visualanalogue scale (mean \pm standard deviation EuroQol visualanalogue scale value: $60.2 \pm 21$ in patients without ICUacquired infection versus $60.6 \pm 22$ in those with ICU-acquired infection). The current general level of health compared with status before ICU admission did not differ between the groups either. Only $36 \%$ of those employed resumed their previous jobs.

Conclusion ICU-acquired infection had no impact on long-term survival. The patients with ICU-acquired infection more frequently experienced problems with self-care than did those without ICU infection, but ICU-acquired infection was not a significant risk factor for diminished self-care in multivariate analysis.

\section{Introduction}

Nosocomial infections increase mortality and costs in intensive care units (ICUs) [1-3]. Furthermore, they increase length of stay in the ICU as well as the frequency and duration of organ failures [4]. We previously showed that ICU-acquired infection was an independent risk factor for hospital mortality, even after adjustment for age and Acute Physiology and Chronic Health Evaluation (APACHE) II and Sequential Organ
Failure Assessment (SOFA) scores, in a series of 335 ICU patients with ICU stay longer than 48 hours [5]. However, long-term outcome has not been studied in detail in patients acquiring an infection during their ICU stay. Studies have shown that sepsis patients who survive critical illness are at greater risk for post-ICU death than are control individuals; furthermore, survivors have been reported to have poor functional outcomes $[6,7]$. Reduced quality of life has also been reported

$\overline{\mathrm{APACHE}}=$ Acute Physiology and Chronic Health Evaluation; ARDS = acute respiratory distress syndrome; $\mathrm{Cl}=\mathrm{confidence}$ interval; EQ-5D = EuroQol five-dimensional questionnaire; $E Q-V A S=$ EuroQol visual-analogue scale; $H R Q O L=$ health-related quality of life; ICU = intensive care unit; $S D$ $=$ standard deviation; SOFA $=$ Sequential Organ Failure Assessment. 
among patients with acute respiratory distress syndrome (ARDS) as compared with critically ill control patients, but postdischarge mortality did not appear to be increased in ARDS patients [8,9]. ICU-acquired infections during critical illness impose a major burden on the costs and outcomes of intensive care; we addressed the question of whether these infections also have an impact on long-term mortality and quality of life in a prospectively study conducted in a subgroup of survivors after discharge.

\section{Materials and methods Study location and population}

The study was conducted in Oulu University Hospital, which is a 900-bed tertiary level teaching hospital. All patients admitted into the ICU during the period from May 2002 to June 2003 whose ICU stay was longer than 48 hours were included in the study. The study protocol was approved by the hospital's ethics committee. The distribution of infections on admission and the epidemiology and contribution of ICU-acquired infections to hospital mortality were reported previously $[5,10,11]$. This substudy concentrated on the situation following hospital discharge.

\section{Study parameters}

For all study patients the following information was collected: age, sex, smoking habits, alcohol abuse, presence of chronic underlying diseases (chronic obstructive pulmonary disease, ischaemic heart disease, chronic hepatic disease, chronic renal disease, previous stroke or transient ischaemic attack, diabetes, malignancy or immunosuppressive medication), severity of underlying diseases and organ dysfunctions on admission (assessed using APACHE II [12] and SOFA [13]), and diagnostic category on admission.

The presence of infection was recorded using criteria required by the US Centers for Disease Control and Prevention (CDC) $[14,15]$ but with the following modifications. A catheterrelated infection was deemed to be present if the same strains of bacteria were isolated in blood cultures and in a semiquantitative catheter tip culture, with no other site of infection. A catheter-related infection was also diagnosed if the patient had a positive semiquantitative catheter tip culture while blood cultures showed no growth or were not done, and there were clinical signs of infection, no other infection site was present and the patient exhibited a favourable response to antimicrobial therapy. Secondary bacteraemia was recorded when the same strains of bacteria were isolated in blood culture and in culture from a site of infection. Ventilator-associated pneumonia was defined according to criteria proposed by an international panel [16]. Pneumonia was diagnosed when a new and persistent infiltrate that was not otherwise explained appeared on chest radiographs, along with the presence of any two of the following: fever (temperature $>38^{\circ} \mathrm{C}$ ) or hypothermia (temperature $<36^{\circ} \mathrm{C}$ ), leucocytosis $\left(>10 \times 10^{3} / \mathrm{mm}^{3}\right.$ ) or leu- copenia $\left(<4.0 \times 10^{3} / \mathrm{mm}^{3}\right)$, and new purulent tracheal aspirate.

Lengths of stay in the ICU and at hospital were recorded. Postdischarge mortality data were obtained from the hospital database, which had been updated with data from Central Statistical Office of Finland on 25 January 2005.

\section{Measurement of health-related quality of life}

Health-related quality of life (HRQOL) was measured using the five-dimensional EuroQol (EQ-5D) questionnaire, which has been described in detail elsewhere [17]. It has been recommended and widely used for measuring HRQOL in critical care [18-21]. In short, the questionnaire contains two parts: the EQ-5D self-classifier, a self-reported description of current health problems according to five items (mobility, self-care, usual activities [work, housework, family and leisure activities, and so on], pain/discomfort and anxiety/depression) each with three response alternatives $(1=$ no problems, $2=$ moderate problems, 3 = severe problems). The second part is a visualanalogue scale (EQ-VAS) ranging from 0 (worst possible health state) to 100 (best possible health state), on which the patients rate their current health. A weighted health state index, the EuroQol 5D Index, based on the five dimensions and ranging from -0.11 ('worse than death') to 1 ('perfect health'), was also calculated [22].

All survivors were mailed the following materials in January 2005: a cover letter explaining the objectives of the study and requesting the patient's or their relatives' collaboration in completing the questionnaire; a copy of the EQ-5D questionnaire; and a form with accessory questions regarding each patient's subjective overall assessment of their health status compared with the situation before ICU treatment and their current employment status. If there was no initial response to the questionnaire, the patients were contacted by phone by a trained ICU study nurse, who repeated the questions on the phone exactly, according to the EQ-5D questionnaire, and asked the patient to answer 'yes' or 'no'.

\section{Data registration and statistical analysis}

The data were entered into a SPSS database (SPSS Data Entry, version 2.0; SPSS Inc., Chicago, IL, USA). Summary statistics for continuous or ordinal variables are expressed as the median with the 25th to 75th percentiles or as the mean and standard deviation (SD). The multivariate Cox regression model was used to assess the impact of ICU infection on longtime survival, whereas the other parameters in the final model were selected on statistical grounds $(P<0.05)$. The log-linearity assumption of the continuous variables was checked by creating a design variable based on quartiles, and the assumption of proportional hazards was evaluated graphically by logminus-log survival plots. Log-rank test results are presented for Kaplan-Meier survival curves. The impact of ICU-acquired infection on EQ-5D self-care (no problems or some problems) 
dimension was evaluated by logistic regression analysis. The linearity assumption of the continuous variable for age did not hold, and a dichotomous covariate at age 50 years $(<50$ versus $\geq 50$ ) was therefore created. Goodness-of-fit was evaluated using the Hosmer-Lemeshow test. The other variables entered into the multivariate Cox and logistic regression models in addition to ICU-acquired infection were the APACHE II score, chronic underlying disease, infection on ICU admission, sepsis, severe sepsis or septic shock on admission, community or hospital-acquired pneumonia on admission, admission diagnostic category (medical, surgical nontrauma, trauma, neurological), ICU length of stay, SOFA score on admission and on ICU discharge, and the normal face validity parameters of age, sex, smoking habits and alcohol abuse. No significant interactions or collinearities between ICU infection and the other parameters in either multivariate model were found. Further, nested models were compared using the likelihood ratio test to select the best model. Two-tailed $P$ values are reported, and the analyses were performed by the SPSS (version 12.0.1; SPSS Inc.) software.

\section{Results \\ Characteristics of intensive care unit admissions}

The study population is presented in Figure 1. The main demographic data and clinical characteristics of 272 patients discharged from hospital are presented in Table 1. There were significantly more patients with trauma on admission among the patients who developed an ICU infection $(P<0.001)$ and more medical admissions among the patients who did not develop an ICU infection $(P<0.001)$. The median APACHE II scores did not differ between the groups, whereas the median SOFA score on admission was higher and the ICU length of stay longer in the group of surviving patients with an ICUacquired infection. The following ICU-acquired infections were recorded in 55 patients: ventilator-associated pneumonia (17), surgical site infections (14), lower respiratory tract infection (14), intra-abdominal infections (6), sinusitis (6), soft tissue or skin infections (4), primary or catheter-associated bacteraemia (2), secondary bacteraemia (1), urinary tract infection (1) and other infections (2).

\section{Outcomes}

Of the 272 patients discharged from hospital, 85 died after discharge (31.3\%). The median follow-up time after hospital discharge for the whole study population was 22 months (25th to 75th percentile: 16 to 26 months) and that for the survivors was 24 months ( 21 to 28 months). This was also the median time for completing the $E Q-5 D$ questionnaire form. Among the patients with no infection on admission, seven patients with an ICU infection (26.9\%) and 10 patients without an infection $(21.7 \% ; P=0.41)$ died. The corresponding numbers of deaths among the patients with infection on admission were as follows: six patients with an ICU infection (27.6\%) and 60 patients without an ICU infection (35.1\%; $P=0.40$ ). The long-term survival curves did not differ between the patients with and those without an ICU-acquired infection (Figure 2). Furthermore, based on the multivariate Cox model, ICUacquired infection did not increase long-term mortality (Table 2). The adjusted hazard ratio for the effect of ICU-acquired infection on posthospital mortality in the multivariable Cox regression model was 0.83 (95\% confidence interval [Cl] 0.47-1.46).

\section{Health-related quality of life}

Quality of life data were obtained from 142 of the 187 survivors $(75.9 \%)$. The questionnaire was completed by the patient in 121 cases $(85.2 \%)$, by relatives in 12 cases $(8.5 \%)$, and by a district or ward nurse in nine cases (6.3\%). A total of 113 respondents returned the questionnaire by mail, and 29 were contacted by phone. The nonrespondents were significantly younger than the respondents, but no significant differences were observed in sex, APACHE II scores, admission diagnostic category, presence of chronic underlying disease, or length of stay in the ICU or in hospital (Table 3). Only 36\% of those employed before the ICU episode $(n=47)$ had resumed their previous jobs, whereas $54.4 \%$ had quit because of the illness that led to ICU admission.

The EQ-5D self-classifier data of the study groups with and without an ICU-acquired infection are presented in Table 4. The patients with an ICU infection had more problems on the self-care dimension $(P=0.004)$, but there were no other differences. However, multivariate analysis did not identify ICUacquired infection to be a risk factor for diminished self-care (odds ratio $=1.71,95 \% \mathrm{Cl} 0.65$ to $4.54 ; P=0.28$; Table 5). Overall, two-thirds of the patients suffered from moderate or extreme pain.

The mean \pm SD value on the EQ-VAS was $60.2 \pm 21$ among the patients without an ICU-acquired infection, and the corresponding figure for those with an ICU-acquired infection was $60.6 \pm 22$. The difference between the means was -0.41 (95\% confidence interval $=-9.30$ to $+8.48 ; P>0.9)$. The mean \pm SD EQ-5D weighted health state index (EuroQol 5D Index) was $0.715 \pm 0.24$ for those without an ICU infection and $0.725 \pm 0.23$ for those with an ICU infection. The difference between the means was $-0.01(95 \% \mathrm{Cl}=-0.11$ to +0.09 ; $P=0.84$ ).

The current general level of health compared with the status before ICU admission did not differ between the groups, because $52(47.7 \%)$ of patients without and $16(57.1 \%)$ of those with an ICU-acquired infection perceived their health status to be worse $(P=0.40)$. The difference between proportions was $-9.4 \%(95 \% \mathrm{Cl}=-28.2 \%$ to $+10.9 \%)$.

\section{Discussion}

Our results show that ICU-acquired infection did not have significant impact on long-term mortality after discharge. Although the patients with an ICU-acquired infection more fre- 
Table 1

Main demographic data and clinical characteristics of patients discharged from hospital

\begin{tabular}{|c|c|c|c|}
\hline Factor & $\begin{array}{c}\text { No ICU-acquired infection } \\
(n=217)\end{array}$ & $\begin{array}{l}\text { ICU-acquired infection } \\
(n=55)\end{array}$ & $P$ \\
\hline Male sex & $133(61.3)$ & $40(72.7)$ & 0.12 \\
\hline Age years & $57(46-68)$ & $57(45.5-67.5)$ & 0.63 \\
\hline \multicolumn{4}{|l|}{ Main reason for admission } \\
\hline Surgical, nontrauma & $73(34.0)$ & $25(45.5)$ & 0.12 \\
\hline Trauma & $18(8.4)$ & $16(29.1)$ & $<0.001$ \\
\hline Medical & $96(44.7)$ & $8(14.5)$ & $<0.001$ \\
\hline Neurological & $21(9.8)$ & $4(7.3)$ & 0.8 \\
\hline Chronic underlying disease & $148(68.2)$ & $33(60.0)$ & 0.27 \\
\hline Current smoker & $82(42.7)$ & $20(40.8)$ & 0.87 \\
\hline Alcohol abuse & $42(19.4)$ & $11(20.8)$ & 0.85 \\
\hline APACHE II score on admission & $22(18-28)$ & $20(17-27)$ & 0.44 \\
\hline SOFA score on admission & $6.0(4.0-8.0)$ & $9.0(6.0-10.0)$ & $<0.001$ \\
\hline SOFA score on ICU discharge & $3.0(2.0-5.0)$ & $3.0(2.0-4.0)$ & 0.26 \\
\hline Infection on admission & $171(78.8)$ & $29(52.7)$ & $<0.001$ \\
\hline Community-acquired pneumonia on admission & $59(27.2)$ & $5(9.1)$ & 0.004 \\
\hline Hospital-acquired pneumonia on admission & $32(14.7)$ & $7(12.7)$ & 0.83 \\
\hline Sepsis on admission & $30(13.8)$ & $3(5.5)$ & 0.11 \\
\hline Severe sepsis on admission & $17(7.8)$ & $0(0)$ & 0.03 \\
\hline Septic shock on admission & $37(17.1)$ & $16(29.1)$ & 0.06 \\
\hline LOS in ICU (days) & $3.75(2.7-5.8)$ & $10(6.2-15.8)$ & $<0.001$ \\
\hline LOS in hospital, days & $17(10-26)$ & $25(17.5-37)$ & 0.62 \\
\hline
\end{tabular}

Values are expressed as median (25th to 75th percentile) or number (\%) of patients. Chronic underlying diseases included chronic obstructive pulmonary disease, ischaemic heart disease, chronic hepatic disease, chronic renal disease, previous stroke or transient ischaemic attack, diabetes, malignancy or immunosuppressive medication. APACHE, Acute Physiology and Chronic Health Evaluation; ICU, intensive care unit; LOS, length of stay; SOFA, Sequential Organ Failure Assessment.

quently experienced problems in self-care (50\%) than did those without an ICU infection (33.2\%; according to EQ-5D), ICU-acquired infection was not a significant risk factor for diminished self-care in multivariate analysis.

To date, there have been no previous studies looking at longterm outcomes of patients with ICU-acquired infections as a whole. Most of the published studies deal with long-term mortality from specific infections, often ones acquired before the ICU admission [6,23-25]. The strengths of our study are the prospective design and the systematic search for various infections on admission and during the ICU stay. The response rate of $75 \%$ for the HRQOL survey was also in accordance with earlier studies using a similar survey method [21,26,27]. Because the nonrespondents were younger and exhibited a trend toward shorter hospital LOS, it is possible that our HRQOL results would have been better if the nonrespondents had also answered. Also, the time frame of more than 48 hours of ICU stay, which is generally used in association with ICU- acquired infections, may result selection bias in favour of very seriously ill patients and overestimation of mortality, as well as underestimation of the results of the HRQOL survey compared with whole ICU populations.

Some limitations of our study should be specifically addressed. Because the study was conducted in a single mixed ICU, there were not enough patients to evaluate the impacts of specific infections on outcome, which should be evaluated in a larger multicentre study. There are several possible explanations for the finding that an ICU-acquired infection did not appear to have an impact on HRQOL or posthospital mortality. Our study population consisted of 272 patients, which was reflected in the wide $95 \%$ Cls. We observed, for example, a 9.4\% difference in the proportions of the variable 'General health compared with pre-ICU situation (worse versus better/similar)' between the two groups. According to power calculations (with $\alpha=0.05$ and $\beta=0.20$, and assuming that $25 \%$ of the patients actually had an ICU- 


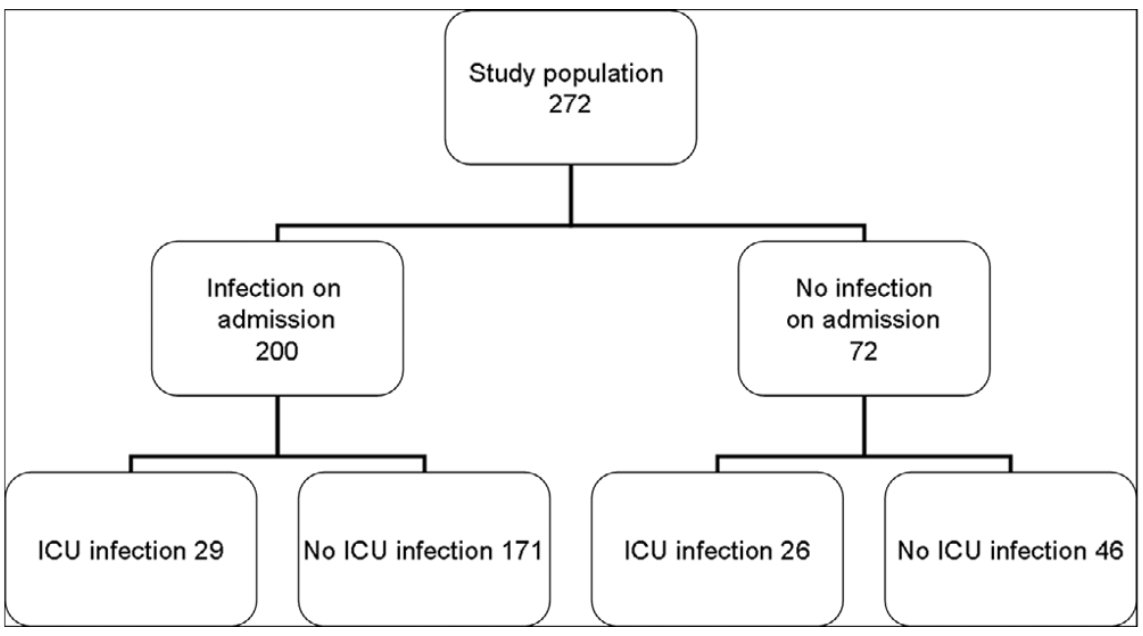

Study population. ICU, intensive care unit.

acquired infection), we would have needed approximately 1,250 patients to prove that the difference was statistically significant. This would have required nine years of data collection with our study protocol in this centre. Another explanation may be the fairly long follow-up time. However, there were no significant differences in median follow-up times (21 months for the patients with and 23 months for those without an ICU infection; $P=0.57$ ), which is an argument against this explanation. The third, and likely, explanation is that the ICUacquired infection really did not have any impact on posthospital mortality or HRQOL.

The present study shows that ICU-acquired infection did not increase long-term mortality after hospital discharge, suggesting that the patients with serious ICU-acquired infections who are likely to die actually die during their hospital stay; ICUacquired infection has been shown to be an independent risk factor for hospital mortality [5]. Similar results were previously reported for ARDS patients [8]. According to our risk model, known factors such as severity of illness, presence of chronic underlying disease, and admission category were risk factors for long-term mortality even in our series [28-30]. Although hospital-acquired pneumonia on admission to the ICU was not a risk factor for hospital mortality, it was a significant risk factor for long-term mortality among the patients surviving hospital discharge. This was most likely due to the more severe underlying diseases in this patient group [10]. Needless to say, ICUacquired infection would not have been entered into the Cox regression model if we had been studying overall long-term mortality among ICU survivors.

Although in our series the majority of respondents reported moderate or good general health after discharge, almost half of them rated their health as worse than before ICU admission. Quality of life was generally reduced to the same extent in patients with and those without an ICU-acquired infection, as measured using the EQ-VAS and the EuroQol 5D Index. There was, however, a difference in one of the dimensions of the EQ5D self-classifier. Namely, patients with an ICU-acquired infection experienced more problems on the self-care dimension than did those without an ICU-acquired infection, but ICUacquired infection was not a significant risk factor for diminished self-care in multivariate analysis. It has previously been shown that follow up-HRQOL reflects preadmission HRQOL [31]. The rate of decline of HRQOL was higher in our series

Table 2

Effect of ICU-acquired infection on posthospital mortality in multivariable Cox regression model

\begin{tabular}{lccr}
\hline Factor & HR & $95 \%$ Cl & $P$ \\
\hline ICU-acquired infection & 0.83 & $0.47-1.46$ & 0.52 \\
APACHE II score on admission & 1.07 & $1.04-1.46$ & $<0.001$ \\
Presence of chronic disease & 3.23 & $1.6-6.54$ & 0.001 \\
Hospital-acquired pneumonia & 2.6 & $1.57-4.33$ & $<0.001$ \\
Surgical reason for admission & 1.93 & $1.23-3.03$ & 0.004 \\
\hline
\end{tabular}

APACHE, Acute Physiology and Chronic Health Evaluation; $\mathrm{Cl}$, confidence interval; HR, hazard ratio; ICU, intensive care unit. 
Figure 2

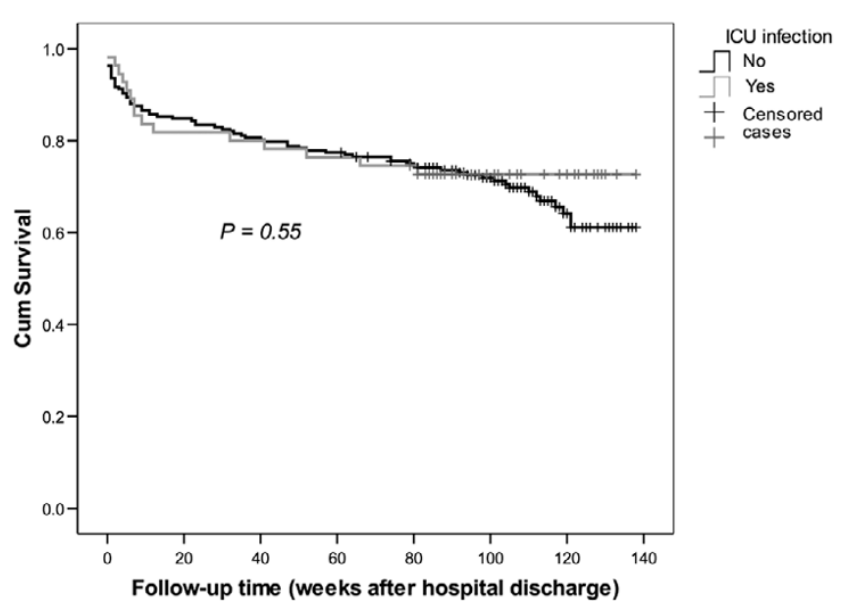

Survival curves of ICU patients after discharge from hospital. The patients who were alive on 25 January 2005 were censored. ICU, intensive care unit.

than in a German study [32] in which the physical and mental components deteriorated in only $14 \%$ and $8 \%$ of the survivors, respectively. The fact that we did not rate the preadmission HRQOL might have had an influence on the patient's perception of the change in HRQOL. However, a baseline assessment was not possible in our patient series. Furthermore, it is known that proxies underestimate patients' quality of life [3335]. In addition to the preadmission HRQOL, the underlying comorbidities, the degree of organ dysfunction, and the length of ICU stay might also have influenced the long-term quality of life. Accordingly, more than $60 \%$ of our patients had a chronic underlying disease, which has been shown to have a signifi- cant effect on post-ICU HRQOL [26]. The degree of organ dysfunction has been shown to be related to the diminished quality of life [32]. Although our patients with ICU-acquired infection had more severe organ dysfunctions on admission, there were no differences at ICU discharge. Some differences in HRQOL have been shown to exist between patients undergoing short-term and those undergoing long-term ICU stays with regard to physical role and vitality [36]. In our series, the patients with an ICU-acquired infection also had a significantly longer ICU stay. The rate of septic shock on admission was higher in the group with ICU-acquired infections, but patients with sepsis and septic shock have been previously shown to regain quality of life similar to that in other critically ill patients [19].

Overall, ICU-acquired infection was not a significant risk factor for diminished self-care in multivariate analysis. Age over 50 years was a risk factor for diminished self-care, whereas smoking and community-acquired pneumonia seemed to be protective factors. Because our aim was to study the significance of ICU-acquired infections for long-term quality of life, this variable was necessarily included in the different models. Hence, the odds ratios of the other parameters are biased because of the incorporation of ICU-acquired infection in the models. Therefore, any conclusions concerning the other parameters should be made with caution. The possibility of random effects in a small sample may naturally be one explanation. Despite their self-care problems, the patients who survived an ICU infection were equally likely to regain their prior general health status as were ICU patients without an ICU-acquired infection.

Two-thirds of the present patients suffered from moderate or

Table 3

Main demographic data and clinical characteristics in respondents and nonrespondents to the EQ-5D questionairre

\begin{tabular}{lccc}
\hline Factor & Nonrespondents & Respondents & $P$ \\
\hline Age (years) & $48(33-59)$ & $57(43-69)$ & 0.008 \\
Sex (male) & $64.4 \%$ & $61.3 \%$ & 0.73 \\
APACHE II score & $23(17-29)$ & $20(17-26)$ & 0.19 \\
Admission diagnostic category & & & 0.15 \\
$\quad$ Trauma & $22.2 \%$ & $12.8 \%$ & 0.06 \\
$\quad$ Surgical, nontrauma & $17.8 \%$ & $33.3 \%$ & 0.86 \\
$\quad$ Medical & $42.2 \%$ & $40.4 \%$ & 0.15 \\
$\quad$ Neurological & $15.6 \%$ & $7.8 \%$ & 0.09 \\
$\begin{array}{l}\text { Presence of chronic underlying } \\
\text { disease }\end{array}$ & $44.4 \%$ & $59.9 \%$ & \\
ICU length of stay (days) & $4.7(3.0-7.0)$ & $4.4(2.8-6.6)$ & 0.82 \\
Hospital length of stay (days) & $14(8-22)$ & $18.5(11-29)$ & 0.05
\end{tabular}

Values are expressed as median (25th to 75th percentile) or number (\%) of patients. APACHE Acute Physiology and Chronic Health Evaluation; EQ-5D, five-dimensional EuroQol; ICU, intensive care unit. 
Table 4

\begin{tabular}{|c|c|c|c|c|c|}
\hline Parameter & $\begin{array}{l}\text { All } \\
\text { respondents }\end{array}$ & $\begin{array}{c}\text { No ICU-acquired infection } \\
\left(n=112 / 147^{a}\right)\end{array}$ & $\begin{array}{l}\text { ICU-acquired infection } \\
\left(n=30 / 40^{a}\right)\end{array}$ & $\begin{array}{l}\text { Difference in proportions } \\
(95 \% \mathrm{Cl})\end{array}$ & $P$ \\
\hline Mobility & & & & & 0.67 \\
\hline No problems & $56(39.4)$ & $46(41.1)$ & 10 (33.3) & $7.7(-12.1$ to +24.6$)$ & \\
\hline Some problems & $74(52.1)$ & $56(50.0)$ & $18(60.0)$ & $-10.0(-27.9$ to +9.9$)$ & \\
\hline Confined to bed & $12(8.5)$ & $10(8.9)$ & $2(6.7)$ & $2.3(-12.9$ to +10.5$)$ & \\
\hline Self-care & & & & & 0.004 \\
\hline Complete & $91(64.1)$ & $76(67.9)$ & $15(50.0)$ & $17.9(-1.3$ to +36.5$)$ & \\
\hline $\begin{array}{l}\text { Some problems in } \\
\text { washing or } \\
\text { dressing }\end{array}$ & $34(23.9)$ & $20(17.9)$ & $14(46.7)$ & $-28.8(-47.0$ to -10.5$)$ & \\
\hline $\begin{array}{l}\text { Unable to wash or } \\
\text { dress }\end{array}$ & $17(12)$ & $16(14.3)$ & 1 (3.3) & $11.0(-3.4$ to +19.1$)$ & \\
\hline Usual activities & & & & & 0.32 \\
\hline No problems & $59(41.5)$ & $50(44.6)$ & $9(30.0)$ & $14.6(-5.3$ to +30.9$)$ & \\
\hline Some problems & $60(42.3)$ & 44 (39.3) & 16 (53.3) & $-14.0(-32.6$ to +5.5$)$ & \\
\hline Unable to perform & $23(16.2)$ & $18(16.1)$ & $5(16.7)$ & $-0.6(-18.4$ to +11.6$)$ & \\
\hline Pain or discomfort & & & & & 0.85 \\
\hline Not at all & $48(34.8)$ & $38(34.9)$ & $10(34.5)$ & $0.4(-19.6$ to +17.7$)$ & \\
\hline Moderate & $80(58.0)$ & $62(56.9)$ & $18(62.1)$ & $-5.2(-23.1$ to +15.0$)$ & \\
\hline Extreme & $10(7.2)$ & $9(8.3)$ & $1(3.4)$ & $4.8(-9.4$ to +12.1$)$ & \\
\hline Anxiety or depression & & & & & 0.91 \\
\hline Not at all & $96(70.6)$ & $74(69.2)$ & $22(75.9)$ & $-6.7(-21.8$ to +13.0$)$ & \\
\hline Moderate & $37(27.2)$ & $30(28)$ & $7(24.1)$ & $3.9(-15.6$ to +18.9$)$ & \\
\hline Extreme & $3(2.2)$ & $3(2.8)$ & $0(0)$ & $2.8(-9.0$ to +7.9$)$ & \\
\hline
\end{tabular}

Values are presented as number (percentage) of patients. aRespondents/all long-term survivors. Cl, confidence interval; EQ-5D, EuroQol fivedimensional questionnaire; ICU, intensive care unit.

extreme pain, supporting the earlier findings that long-term pain and depression may persist even after patients have restored their physical capacity $[21,27]$. In addition, two-thirds of employed respondents had not resumed their previous jobs by the time of the questionnaire survey, mainly because of the illness that led to their ICU admission; the figure is similar to that earlier reported for ARDS survivors [37]. This may have a significant influence on families and society.

\section{Conclusion}

ICU-acquired infection did not independently influence longterm survival or quality of life after hospital discharge in this

Table 5

Effect of ICU-acquired infection on diminished self-care in multivariate logistic regression analysis

\begin{tabular}{lccc}
\hline Factor & OR & $95 \% \mathrm{Cl}$ \\
\hline ICU-acquired infection & 1.71 & $0.65-4.54$ & 0.28 \\
Hospital-acquired pneumonia & 4.31 & $0.89-20.88$ \\
Age $(\geq 50$ versus $<50$ years) & 2.75 & $1.04-7.29$ & 0.07 \\
Current smoker & 0.35 & $0.13-0.91$ & 0.04 \\
Community-acquired pneumonia & 0.27 & $0.08-0.89$ & 0.03 \\
\hline
\end{tabular}

-2 Log likelihood 137.700, P (Hosmer and Lemeshow test) = 0.898. Cl, confidence interval; ICU, intensive care unit; OR, odds ratio. 
series. Our results should be verified in a prospective multicentre study.

\begin{tabular}{l}
\hline Key messages \\
ICU-acquired infection did not affect long-term mortality \\
in patients surviving hospital discharge. \\
- Those surviving an ICU infection regained a similar qual- \\
ity of life, compared with their pre-ICU situation, as did \\
those without an ICU infection. \\
Patients with an ICU-acquired infection experienced \\
more problems in self-care than did those without an \\
ICU-acquired infection. However, ICU-acquired infec- \\
tion was not a significant risk factor for diminished self- \\
care in multivariate analysis.
\end{tabular}

\section{Competing interests}

The authors declare that they have no competing interests.

\section{Authors' contributions}

PY participated in the design of the study and the acquisition and analysis of data, and drafted the manuscript. TA-K, JL and HS participated in the design of the study and analysis of data, and drafted the manuscript. PO participated in the design of the study and performed the statistical analysis. All authors read and approved the final manuscript

\section{References}

1. Vincent JL, Bihari DJ, Suter PM, Bruining HA, White J, NicolasChanoin M, Wolff M, Spencer RC, Hemmer M: The Prevalence of Nosocomial Infection in Intensive Care Units in Europe: Results of the European Prevalence of Infection In Intensive Care (EPIC) Study. JAMA 1995, 274:639-644.

2. Appelgren P, Hellstrom I, Weitzberg E, Soderlund V, Bindslev L, Ransjo U: Risk factors for nosocomial intensive care infection: a long-term prospective analysis. Acta Anaesthesiol Scand 2001, 45:710-719.

3. Rello J, Ollendorf DA, Oster G, Vera-Llonch M, Bellm L, Redman R, Kollef MH, VAP Outcomes Scientific Advisory Group: Epidemiology and outcomes of ventilator-associated pneumonia in a large US database. Chest 2002, 122:2115-2121.

4. Sanchez-Velazquez LD, Ponce de Leon Rosales S, Rangel Frausto MS: The burden of nosocomial infection in the intensive care unit: Effects on organ failure, mortality and costs. A nested case-control study. Arch Med Res 2006, 37:370-375.

5. Ylipalosaari $\mathrm{P}$, Ala-Kokko TI, Laurila J, Ohtonen $\mathrm{P}$, Syrjälä H: Intensive care acquired infection is an independent risk factor for hospital mortality: a prospective cohort study. Crit Care 2006, 10:R66.

6. Heyland DK, Hopman W, Coo H, Tranmer J, McColl MA: Longterm health-related quality of life in survivors of sepsis. Short Form 36: a valid and reliable measure of health-related quality of life. Crit Care Med 2000, 28:3599-3605.

7. Perl TM, Dvorak L, Hwang T, Wenzel RP: Long-term survival and function after suspected gram-negative sepsis. JAMA 1995, 274:338-345

8. Davidson TA, Rubenfeld GD, Caldwell ES, Hudson LD, Steinberg $\mathrm{KP}$ : the effect of acute respiratory distress syndrome on longterm survival. Am J Respir Crit Care Med 1999, 160:1838-1842.

9. Davidson TA, Caldwell ES, Curtis JR, Hudson LD, Steinberg KP: Reduced quality of life in survivors of acute respiratory distress syndrome compared with critically ill control patients. JAMA 1999, 281:354-360.

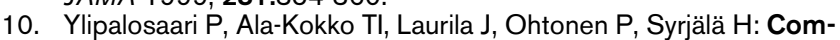
munity- and hospital-acquired infections necessitating ICU admission: spectrum, co-morbidities and outcome. $J$ Infect 2006, 53:85-92.

11. Ylipalosaari $\mathrm{P}$, Ala-Kokko TI, Laurila J, Ohtonen $\mathrm{P}$, Syrjala H: Epidemiology of intensive care unit (ICU)-acquired infections in a 14-month prospective cohort study in a single mixed Scandinavian university hospital ICU. Acta Anaesthesiol Scand 2006, 50:1192-1197.

12. Knaus WA, Draper EA, Wagner DP, Zimmerman JE: APACHE II: a severity of disease classification system. Crit Care Med 1985, 13:818-829.

13. Vincent JL, de Mendonca A, Cantraine F, Moreno R, Takala J, Suter $\mathrm{PM}$, Sprung CL, Colardyn F, Blecher S: Use of the SOFA score to assess the incidence of organ dysfunction/failure in intensive care units: Results of a multicenter, prospective study. Crit Care Med 1998, 26:1793-1800.

14. Garner JS, Jarvis WR, Emori TG, Horan TC, Hughes JM: CDC definitions for nosocomial infections, 1988. Am J Infect Control 1988, 16:128-140.

15. Horan TC, Gaynes RP, Martone WJ, Jarvis WR, Emori TG: CDC definitions of nosocomial surgical site infections, 1992: a modification of CDC definitions of surgical wound infections. Infect Control Hosp Epidemiol 1992, 13:606-608.

16. Rello J, Paiva JA, Baraibar J, Barcenilla F, Bodi M, Castander D, Correa H, Diaz E, Garnacho J, Llorio M, et al:: International Conference for the Development of Consensus on the Diagnosis and Treatment of Ventilator-associated Pneumonia. Chest 2001, 120:955-970.

17. Brooks R: EuroQol: the current state of play. Health Policy 1996, 37:53-72.

18. Angus DC, Carlet J, 2002 Brussels Roundtable Participants: Surviving intensive care: a report from the 2002 Brussels Roundtable. Intensive Care Med 2003, 29:368-377.

19. Granja C, Dias C, Costa-Pereira A, Sarmento A: Quality of life of survivors from severe sepsis and septic shock may be similar to that of others who survive critical illness. Crit Care 2004, 8:R91-R98.

20. Granja C, Teixeira-Pinto A, Costa-Pereira A: Quality of life after intensive care: evaluation with EQ-5D questionnaire. Intensive Care Med 2002, 28:898-907.

21. Garcia Lizana F, Peres Bota D, De Cubber M, Vincent JL: Longterm outcome in ICU patients: what about quality of life? Intensive Care Med 2003, 29:1286-1293.

22. Calculating the US Population-based EQ-5D Index Score [http://www.ahrq.gov/rice/EQ5Dscore.htm]

23. Weycker D, Akhras KS, Edelsberg J, Angus DC, Oster G: Longterm mortality and medical care charges in patients with severe sepsis. Crit Care Med 2003, 31:2316-2323.

24. Sasse KC, Nauenberg E, Long A, Anton B, Tucker HJ, Hu TW: Long-term survival after intensive care unit admission with sepsis. Crit Care Med 1995, 23:1040-1047.

25. Kriwanek S, Armbruster C, Dittrich K, Beckerhinn P, Schwarzmaier $A$, Redl E: Long-term outcome after open treatment of severe intra-abdominal infection and pancreatic necrosis. Arch Surg 1998, 133:140-144.

26. Orwelius L, Nordlund A, Edell-Gustafsson U, Simonsson E, Nordlund $P$, Kristenson $M$, Bendtsen $P$, Sjoberg F: Role of preexisting disease in patients' perceptions of health-related quality of life after intensive care. Crit Care Med 2005, 33:1557-1564.

27. Pettila $V$, Kaarlola $A$, Makelainen $A$ : Health-related quality of life of multiple organ dysfunction patients one year after intensive care. Intensive Care Med 2000, 26:1473-1479.

28. Niskanen $M$, Kari $A$, Halonen $P$ : Five-year survival after intensive care: comparison of 12,180 patients with the general population. Finnish ICU Study Group. Crit Care Med 1996, 24:1962-1967.

29. Ridley S, Jackson R, Findlay J, Wallace P: Long term survival after intensive care. BMJ 1990, 301:1127-1130.

30. Keenan SP, Dodek P, Chan K, Hogg RS, Craib KJ, Anis AH, Spinelli JJ: Intensive care unit admission has minimal impact on long-term mortality. Crit Care Med 2002, 30:501-507.

31. Wehler M, Martus P, Geise A, Bost A, Mueller A, Hahn EG, Strauss $\mathrm{R}$ : Changes in quality of life after medical intensive care. Intensive Care Med 2001, 27:154-159.

32. Wehler M, Geise A, Hadzionerovic D, Aljukic E, Reulbach U, Hahn $E G$, Strauss R: Health-related quality of life of patients with multiple organ dysfunction: individual changes and compari- 
son with normative population. Crit Care Med 2003, 31:1094-1101.

33. Hofhuis J, Hautvast JL, Schrijvers AJ, Bakker J: Quality of life on admission to the intensive care: can we query the relatives? Intensive Care Med 2003, 29:974-979.

34. Granja C, Azevedo LF: When (quality of) life is at stake and intensive care is needed: how much can we trust our proxies? Intensive Care Med 2006, 32:1681-1682.

35. Scales DC, Tansey CM, Matte A, Herridge MS: Difference in reported pre-morbid health-related quality of life between ARDS survivors and their substitute decision makers. Intensive Care Med 2006, 32:1826-1831.

36. Stricker KH, Cavegn R, Takala J, Rothen HU: Does ICU length of stay influence quality of life? Acta Anaesthesiol Scand 2005, 49:975-983.

37. Herridge MS, Cheung AM, Tansey CM, Matte-Martyn A, Diaz-Granados N, Al-Saidi F, Cooper AB, Guest CB, Mazer CD, Mehta S, et al.: One-year outcomes in survivors of the acute respiratory distress syndrome. N Engl J Med 2003, 348:683-693. 